\title{
Integrating Co-development and Fit Coordination
}

\author{
Edmilson Rampazzo Klen and Luiz Salomão Ribas Gomez \\ EGR - Graphic Expression Department, \\ UFSC - Federal University of Santa Catarina, Florianópolis-SC, Brazil \\ \{erklen, salomao\} @cce.ufsc.br
}

\begin{abstract}
In the last recent years the globalized world has experienced its most amazing and rapid technological evolution. The repercussions and consequences of this (re-)evolution are many and can be seen and felt in the behavior of the enterprises and the consumers. For enterprises, new organizational structures are taking place contributing even for the emergence of the scientific discipline called Collaborative Networks. For consumers, a more active - and less reactive - role is gaining evidence and being directly influenced by the advances on information and communications technologies. The new web generation is participating in a silent movement of creation of prosumers1. As a consequence of this change in the behaviour of the enterprises and the consumers, a new space comes up with a high potential to be exploited. This space is seen as: products co-design or co-development environment. However, to lead the organizations in this collaborative relationship is necessary a fit coordination with specific competences to each case.
\end{abstract}

Keywords: Co-development, Competences, Fit coordination.

\section{Introduction}

Nowadays, consumers are dominating the Information and Communicate Technologies (ICT) advances, where, through them, their wishes became more transparent and available.

This is possible because their wishes are also discussed in the social nets, like communities, where producers can also participate to recognize these wishes of these (future) customers. In some cases, it is possible to observe in this kind of communities, discussion about a specific product that the consumers use or what they would like to use.

This scenario persuades towards a production addressed to these communities and, in some cases, in an individual form.

But is not enough to know what the market wishes, it is necessary to recognize the adequate organizations those will work together to attend the market.

The discipline Collaborative Network appears like a fundamental part to support this new evolutionary relationship among consumers and the organizations facilitating the joint of competences through new organizational structures, putting together appropriate organizations to attend the wishes of the consumers that arise by social nets of communities.

\footnotetext{
${ }^{1}$ Prosumer is the result of the contraction of the words: producer + consumer, Toffler [1]
} 
Authors like Thomas Friedman and John Gattorna take account the value related to the new globalization and the persons.

Successful companies agree that the person behind the transaction must also be considered. Such customer-focused and more flexible configurations are actually fundamental components of different supply chains. We are foreshadowing a new understanding of the way enterprises will work in the future [2]. Based on revolutions like the internet, cell phone, optic fiber, and so on, not just enterprises but also the individuals can act in an extended environment [3].

Is growing in this moment, a large volunteer business net shaping the prosumer concept also seen like talent pools. The smart enterprises have been using this potential to develop new and strong business models and systems [4].

This scenario (Figure 1) based on ICT is then composed by: 1) Customers or future customers creating social nets of communities that exchange ideas among them about new products or about improvements of products that already are in the market (i.e. Prosumer Communities). 2) Organizations supported by Collaborative Network always interested to know the wishes of the market. 3) The interaction between these parts that will facilitate the ideas exchange among producer and consumers to better know the market wishes and will also facilitate the choice of organizations that will work together (i.e. Virtual Organizations-VO) to attend the market more accurately (Toward Production). This ideas exchange environment will be here called Codevelopment Environment.

To complete this scenario is necessary an adequate management, an adequate coordinator. This person should be prepared to work with this market evolution related to the technological development of the production systems as well as of the information technology. The coordinator search \& suggestion methodology proposed for this scenario is here called fit coordination.

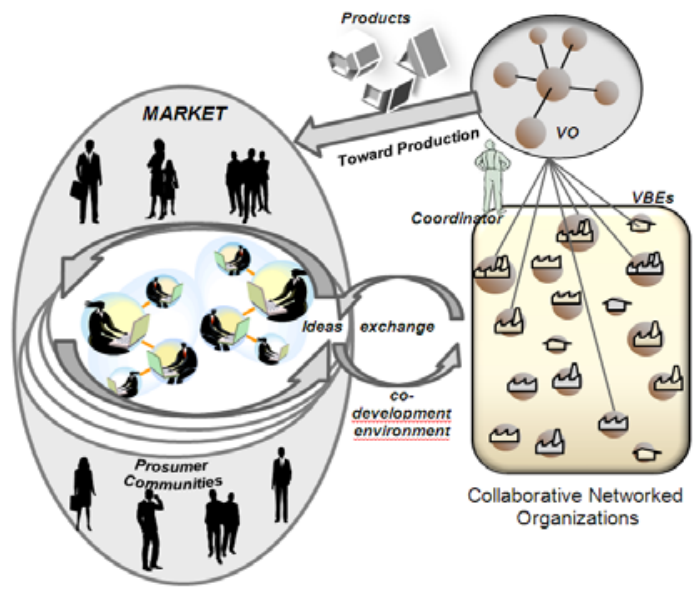

Fig. 1. The Scenario 


\section{The Co-development Environment}

The fact is that functional organization, which have served us so well for so long, together with matrix and partnership variants, are being rapidly marginalized. This is happening as increasing competitive intensity in many industry-market combinations drives customers towards more aggressive and demanding buying behaviors [2]. These new organizational structures are been shaped in the last years based on the Collaborative Networked Organizations concepts [5].

In the case of the consumers a more active role - and less reactive - can be observed in the last years, where this behavior change is directly influenced by the facility of the access of new tools based on ICTs (Fig. 1). Environments, where there are ideas changes about a product or service (available on the market) support the mass collaboration.

The prosumers potentiate the co-development process in a very effective way mainly about their suggestions of design and usability. This is possible nowadays with a "home technology" - like the available in a social relationship - where is also possible to be applied with more details through the use of free CAD systems available on the internet, i. e. Google SketchUp [6].

The enterprises can now be integrated in this social net to find out new business opportunities. Some collaborative networked structures can help this interaction in a more organized form, i.e. Virtual Breeding Environment (VBE) and Virtual Teams (VT).

The VBE, that represents an association of organizations that share resources and skills to achieve a goal [7], has now the possibility to acquire new opportunities through this near contact with the prosumer communities. The ideas exchange with these future customers give a more detailed way to the wishes/necessities of the market providing a co-design and/or co-development environment.

The VT is a temporary group of professionals that work together towards a common goal such as realizing a consultancy job, a joint project, etc, and that use computer networks as their main interaction environment [8]. VT could be created with some personal competences to know and to evaluate the ideas/necessities/wishes in different viability aspects (technological, economics, social, etc). Professionals from different enterprises previously prepared to develop new ideas of new products can now work together just to evaluate these ideas coming direct from consumers or group of consumers. Moreover, the VT could also help the VBE administration staff to select the more appropriated enterprises - in a Virtual Organization (VO) structure - to attend a selected idea.

The VO would be a similar structure like the VT but, in this case, shaped with organizations/enterprises. The definitions of a VO often assume that it behaves and can be managed in some way like a single organization [9]

This co-design and/or co-development environment enables a "toward production", in other words, a product would come to the market incorporating strong feelings of a large group of persons with more chance to be a success in the market. In a virtuoso cycle this product would be continuously analyzed by this kind of consumers to other improvements enabling a long life in the market. 


\section{Fit Coordination}

A good idea and an appropriate infrastructure are very important to the production of a new product but, to the work with collaborative structures - with different organizations with different visions, technologies, cultures, and so on, - a competent coordination of this structure is also essential.

Many organizations use the concept of competence to both measure and improve employee development as well as during their recruitment process.

The terminology of "competence" can be confusing because each organization normally has its own interpretation and understanding for the term.

Along the time many researchers have been studying competence. One of the wellestablished definitions on competence is provided by Durand [10] who states that competence is the ability to coordinate activities to the standards and rules required in the organization using an appropriate mix of knowledge, skill and attitude. According to him, these three dimensions must be present if someone wants to be effective in the coordination place. This understanding of competence is the one that will be used in this work.

As the VO coordinator has to deal with a distributed, dynamic and - sometimes complex organizational environment one of his/her main attributes should be to adequately balance these dimensions of knowledge, skill and attitude in order to contribute to the achievement of the VO goals. As a direct consequence for all competences, Individual Competences - based on individual needs-, should always have a special attention.

Some essential Competencies of a VO Coordinator can be selected, extended and detailed according to the interest of a VT (composed, i.e, by experts from the VBE members) with the supervision of the VO Planner and the VBE Administrator for instance.

These competencies data can be gathered in a Competence Map where the data can be classified in the three dimension in an integrated form (Knowledge, Skill and Attitude) (Fig. 2), aiming to facilitate the recognition of an adequate candidate in the search and suggestion process.

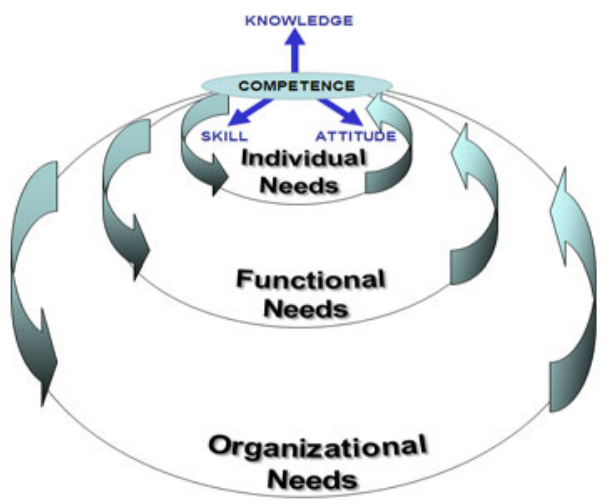

Fig. 2. Competence Cycle 
A very crucial issue for the elaboration of the Competence Map is the use of an adequate Competence Common Ontology as well as the proposition of mechanisms necessary for using and evolving this ontology during the VBE/VO management. It is not the scope of this work to go deeper on this subject. However, given its relevance for the accuracy of this work, the scenario here presented (Fig. 3) is considered deterministic i.e. it is assumed that an ontology exits and is in use.

This competence cycle integrates three complementary competencies types: Individual Competences (the ones related to each individual person), Functional Competences (the ones required by the role to be performed - in this case the VO coordinator) and Organizational Competences (the ones necessary to achieve the objectives of the VO). The synergy among these competences potentializes the latent capacity of the individuals and contributes to leverage the results that can be achieved for the identified needs. The competences serve to fulfil the needs; and the needs serve to instigate competences.

\subsection{A Methodology for a Coordinator Search and Suggestion}

The coordinator(s) search and suggestion is a very important step in the VO life cycle, occurring normally in the Creation phase and - sometimes - in the Evolution phase. This step can be taken making use of the human resources available in the VO environment. The VBE can be an inexhaustible source for this kind of resources. Its members are organizations that have the knowledge of how to work in a Collaborative Network and, in some cases, already have persons with the required competences to manage a VO. Besides tangible goods or the traditional support services offered in the $\mathrm{VBE}$, it is also possible to find this specific service for $\mathrm{VO}$ coordination. In some cases organizations may be elected/selected to act in a business "just" as VO coordinator. Furthermore the trust environment in force in the VBE cares for the quality and the accuracy of the information provided by the VO candidates.

This new "role" of VO Coordinator will most probably require in the near future specific training and educational programmes focusing on the VO management requirements. This will enlarge the universe of choices and will certainly contribute to a more sustainable VO management. This coordination should not be done essentially by a member belonging in the production process but must be a person with adequate competence for this specific VO and also has the acceptance of the VO members.

Based on Klen [11] an appropriated VO coordinator it is suggested the use of a methodology for searching and suggesting like the detail in Figure 3 that works with the 3-Steps:

- STEP 1 - would be the register of VO Coordinator candidates where, these potential candidates, belong to the VBE or belong to a related PVC (Professional Virtual Communities) or are professionals outside of the VBE but indicated by VBE members. Organizations belonging to a VBE may be represented by more than one candidate. In this case the candidates must respect the non-conflict of interest agreement with its own employer.

- STEP 2 - would be the Information Management where the VO candidates' Competence Maps are stored in a Data Base for future use by the VT (supported by VBE Administrator and/or by the VO Planner). 
- STEP 3 - would be the VO Coordinator search (and suggestion). This methodology normally takes place during the Creation (or Evolution) phase. For each business opportunity a different VO is created. Consequently each VO has its own specific needs and requirements which are identified and analysed by VT, always supported by the VBE Administrator and the VO Planner. Based on the VO needs some organizational competences are mapped. These ones constitute the basis for the VBE Administrator/VO Planner to search for specific VO Coordinator competences. In this methodology this step is a human-based one but it can also be performed in an automatic or semi-automatic way provided by an applied intelligence technique. Additionally the VBE Administrator/VO Planner can also set some preferences and/or constraints (e.g. they can apply filters and look for candidates from just a given organization).

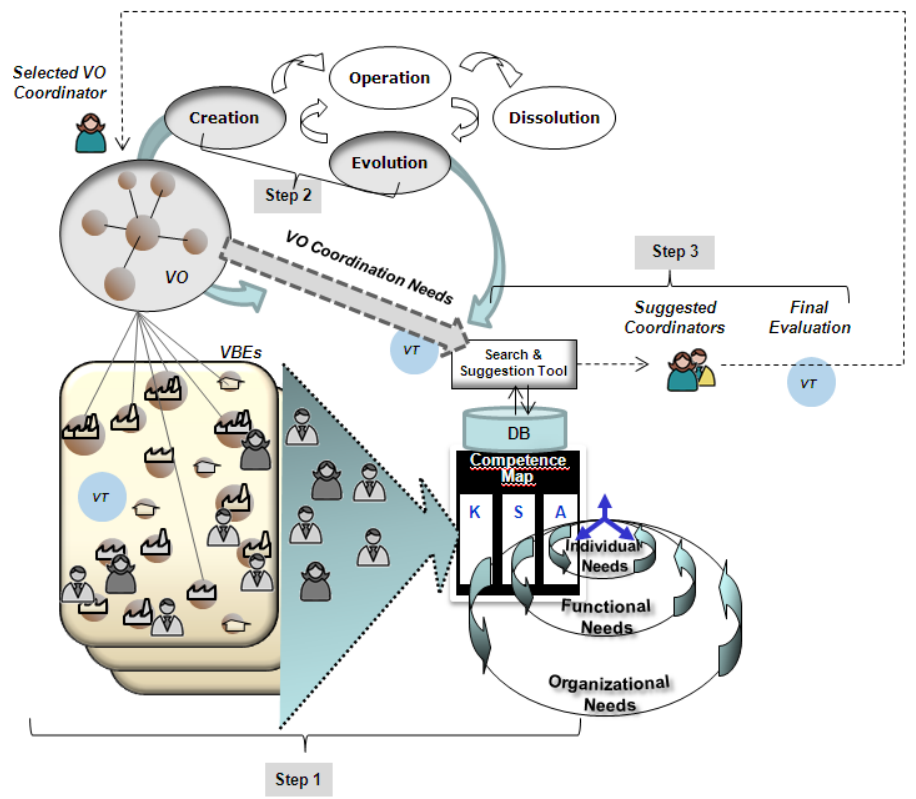

Fig. 3. Methodology for a Coordinator Search \& Suggestion

\section{Integrating Co-development and Fit Coordination}

In a summarized vision, when a good idea is observed during the ideas exchange, the VBE can quickly form a VO, with adequate organizations, to produce i.e. a new product. With the methodology for a coordinator search \& suggestion a coordinator can be also quickly selected based on the best competencies to lead this specifically $\mathrm{VO}$ to the success.

These different collaborative environments could be put together to facilitate the relation between the market and the producers (Fig. 4).

The market wishes/necessities would be appreciated by experts (VT) in different areas (technical, marketing, economy, etc.). Based on this analysis, the VT would indicate the best enterprises to compose the VO to produce the selected idea(s) and, 
based on the VO coordination needs, could also select an appropriated VO coordinator through the search\&suggestion tool/methodology. This selection could, again, be analyzed by the VT based on the competencies of a person related on the VO coordination needs. This fit coordination would support the collaborative environments to make viable towards a production enabling for these new products (or services) a longer live and more success in the market.

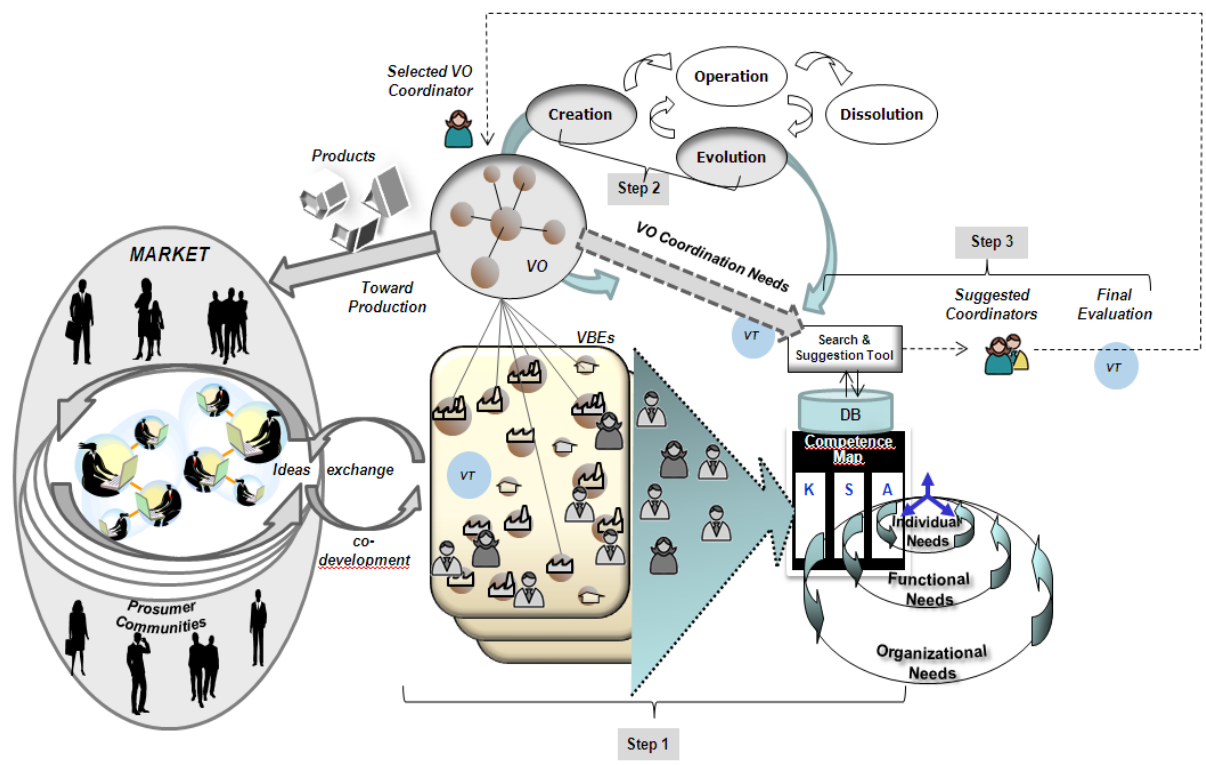

Fig. 4. Collaborative design/development environment supported by a fit coordination

\section{Conclusion}

The new mass collaboration is changing the way how enterprises and societies use the knowledge and the innovation capacity to create value [4].

The quick and close contact with the prosumers' necessities and wishes will demand changes in the work style of the enterprises in the production chain (i.e. VO) pressing them to an expressive collaborative work mainly in the information aspects.

All business areas should be prepared to attend this new market based on customers that want to collaborate. Information previously handled just by members from a production chain (i.e. marketing, production, logistics, development, etc.) can be also influenced by customer. In this new scenario, customers want collaborate not just about a specific product but, more beyond, expressing opinion about the hole product life cycle.

VBE members can, in this case, use this potential to develop new and stronger business models.

The customer evolution has a tendency to be amplified in future mainly in sustainability and in innovation aspects but, to better observe the customer necessities and wishes, proceedings should also be implemented in the VBE to guarantee the information quality. 
If we are sensitive to customer needs and buying preferences, it will be obvious what we have to do, we won't have to worry so much about our competitors - they'll be worrying about us [2].

A good idea isn't qualified just by its creativity and engineering but also by the viability, in other words, an adequate coordination is an essential part of the success of a product in the market and for the collaborative work.

The scenario presented in this paper, is based on the knowledge of the authors on the Collaborative Network area and on the work of the project Ecolead [12]. As a second step, this scenario will be adequate to be used in a new project, in the area of "Design for All', understood as an intervention on environments, products and services with the aim that everyone, including future generations, regardless of age, gender, capabilities or cultural background, can enjoy participating in the construction of our society, with equal opportunities participating in economic, social, cultural, recreational and entertainment activities while also being able to access, use and understand whatever part of the environment with as much independence as possible [13].

\section{References}

1. Toffler, A.: The Third Wave. Bantam Books, USA (1980) ISBN 0-553-24698-4

2. Gattorna, J.: Living Supply Chains. Prentice Hall, Englewood Cliffs (2006) ISBN 0-27370614-4

3. Friedman, T.: The world is flat: a brief history of the twenty-first century. Farrar, Straus and Giroux, USA (2005) ISBN 0-374-29288-4

4. Tapscott, D., Williams, A.D.: Wikinomics - How Mass Collaboration Changes Everything. Penguin Books (2006) ISBN 978-1-59184-138-8

5. Camarinha-Matos, L.M., Afsarmanesch, H.: Collaborative Networked Organizations. Kluwer Academic Publishers, Dordrecht (2004) ISBN 1-4020-7823-4

6. Google, SketchUp, http: / / sketchup.google. com (access: May 26, 2010)

7. Camarinha-Matos, L.M., Afsarmanesh, H.: The Virtual Enterprise Concept. In: Infrastructures for Virtual Enterprises - Networking Industrial Enterprises. IFIP, Kluwer Academic Publishers, Dordrecht (1999) ISBN 0-7923-8639-6

8. Ecolead Project, IST-506958, European Collaborative Networked Organizations Leadership Initiative, D52.2 - Rough reference model for Collaborative Networks (2005), http: / /ecolead.vtt.fi/

9. Camarinha-Matos, L.M., Afsarmanesh, H., Ollus, M., Ecolead: A Holistic Approach to Creation and Management of Dynamic Virtual Organizations. Springer, Heidelberg (2005) ISBN 0-387-28259-9

10. Durand, T.: Strategizing for innovation: competence analysis in assessing strategic change. In: Sanchez, R., Heene, A. (eds.) Competence-based Strategic Management. John Wiley \& Sons, Chichester (1997)

11. Klen, E.R.: Methodology for Virtual Organizations Managers Search and Suggestion based on Individual Competences. 216p. Thesis (Doctor in Production Engineering) in Portuguese - Post-Graduate Program in Production and Systems Engineering, UFSC, Brazil, Florianópolis - SC (2007)

12. Ecolead Project, IST-506958, European Collaborative Networked Organizations Leadership Initiative, http: / / ecolead.vtt.fi/

13. Design for All Foundation, published dossier (2011), http://www.designforall.org 